\title{
Genomic Designing of Climate Smart Turmeric
}

Bandi Arpitha Shankar

Department of Agriculture Biotechnology, Sardar Vallabhbhai Patel University of

Agriculture and Technology, correspondence: projectresearch2019@gmail.com

ORCiD: 0000-0002-7077-2677

\begin{abstract}
:
Turmeric is highly tolerant to several climatic changes and can grow under high temperatures and moderate drought conditions. This herb is very much dependant on optimum rainfall, optimum heat with less chilling or freezing conditions. These conditions if are more than normal would tend to reduce the yields of the crops and also effect the productivity. To reduce such drastic yield losses certain conventional plant breeding methods were employed but were very less effective compared to plant biotechnology. To reduce these loses by stresses, extensive and effective molecular biology methods were employed which identifies the genes that are stress responsive along with certain methods like gene transfer, genetic engineering were also known to be effective. All these methods are quite helpful in mitigating the yield losses and promoting healthy growth in the plants. The maintenance of rhizome size, curcumin content, essential oils etc. is very much necessary for the turmeric crop because of its role especially in medical field. Therefore, the yield losses are reduced to a maximum extent so that development of smart turmeric is easy and crop designing is possible only with the advanced techniques involved in agriculture biotechnology.
\end{abstract}

Key words: Turmeric, Climate change, Improved nutrition, Smart turmeric, Conventional methods, Molecular biology.

\section{Introduction}

Agriculture is highly vulnerable to the changes in the climatic conditions and it is highly affected by different environmental factors. Climate is considered as a main source of nutrition for the growth and wellbeing of several agricultural crops. Many crops depend upon the climatic conditions at different stages of their life cycle i.e., vegetative, reproductive and maturity stages. Several losses are observed in the field level due to changes in climatic conditions. Also, the life cycle of several crops is altered due to climatic effect. In many cases seeds undergo dormancy mainly because of unfavourable climatic conditions[1]. Even if conditions are favourable the germination of the seed would take place whereas the growth of the sapling might be arrested. Matured crops show yield losses and certain signs of death like drooping, withering etc[2].

Drought, flooding, temperatures, cold conditions, heat waves etc. contribute to changes in normal climatic conditions. These conditions create a havoc in the plants and humans effecting their livelihood and development. These conditions are almost similar to several abiotic stresses apart from salinity and soil acidity, the rest of the abiotic stress appeal to severe climatic changes and leads to several agricultural losses. These harmful climatic conditions disturb the plant growing period, effects the yield of several crops and minimise the production of important plant cultivars effecting the GDP of the country and also lives of several farmers[3]. 
There are several factors which cause differences in climatic conditions and leading to environmental disturbances which include deforestation, nitrogen containing fertilizers, gases releasing fluorine, fossil fuels, greenhouse gases and global warming. To our surprise agriculture alone contributes to more than $7 \%$ release of unwanted or harmful gases which would increase the greenhouse gases. Majority of the trees are cut down for wood purpose, paper etc, which causes afforestation leading to the build-up of carbon dioxide gas in the environment because of the lack of living trees as these trees absorb and store the carbon dioxide gases[4]. Also increased usage of fuels like coal, gas and oil which would increase the transportation and pretty much beneficial for the industries but leading to the reduction in the natural resources and also severe accumulation of harmful and poisonous gases in atmosphere[5].

The release of several industrial wastes into the water bodies like rivers and lakes leads to the acid build up and killing microorganism and water plants, sometimes these acids through sublimation process may lead to acid rains. Acid rains are a serious threat in present day agriculture because these rains change the nature of the plants by making them more poisonous for consumption leading to ill health and several ailments. These climatic changes directly or indirectly effect the growth and the nature of the crop[6]. In some cases, like high temperatures makes the crop dry by the lack of moisture and reducing the availability of water to the plants. There are several other factors on how stress would affect the plant growth and development where the seed production and the shelf life of several crops is affected and reduced greatly. The floods in some parts of the country would uproot the plants and also result in leeching of several important nutrients from the soil thereby spoiling the soil environment and soil micro and macro minerals which is a devastating after effect[7]. In chilling conditions certain plants tend to undergo dormancy due to unfavourable conditions like sugarcane, rice, ground nut etc which is major problem to the farmer where the life cycle of the crop is greatly affected leading to retarded growth of the plants[8].

In our review we concentrated on the golden spice that is Turmeric and its sustainability in different climatic conditions. Though turmeric and its family members belong to tropical and sub-tropical regions they can tolerate heat up to a certain level but show certain symptoms like leaf scorching, drooping and dryness due to high temperature conditions[9]. Turmeric is a major cash crop in India due to its several health, beauty and medicinal properties. The importance of turmeric is due to its major polyphenolic compound called curcumin which is about $5-6 \%$ of the total compound in the turmeric plant. This herb is mainly used as a spice in Indian culinary and a major cooking ingredient all over the world. Also this plant contain several advantages as it is used in Ayurveda to cure several health problems and is major compound in many treatments. Some medicated creams are prepared using turmeric as it contains several antiseptic properties and is very helpful in wound healing. Also the by-product of turmeric which is called kum-kum is a major compound for Indian women as a traditional make up[10].

Turmeric is having several advantages of curing certain cancers, heart diseases, improving digestions and curing asthma and lung associated problems. But in recent years concerns have been raised on the growth and development of this herb due to devastating changes in climate form past years which creating a major problem in turmeric and several other crops[11]. Also these stressful climatic conditions would effect the traditional and modern breeding methods which has been an major problem and a serious threat to mankind. The response of different 
stages of the crop to different climatic conditions plays a major role in identifying whether the crop is really able to tolerate or susceptible to harsh environmental conditions[12]. These climatic changes tends to play a major role in altering nutritional qualities in turmeric leading to retarded growth and reduced medicinal properties in plants.

Nutrition in turmeric [8]:

\begin{tabular}{|l|l|}
\hline Important constituents & Percentage \\
\hline Protein & $6.5 \%$ \\
\hline Moisture & $3.5 \%$ \\
\hline Fiber & $2.5 \%$ \\
\hline Fats & $5 \%$ \\
\hline Carbohydrates & $70 \%$ \\
\hline Mineral matter & $3.7 \%$ \\
\hline Curcuminoids & $3-8 \%$ \\
\hline
\end{tabular}

Carbohydrates are the most abundant components in turmeric which is about $70 \%$ and fiber is least observed which is only around $2.5 \%$ overall. Rest of the important factors like fats, moisture and minerals are around 3-5\%. Whereas the most important compounds that are curcuminoids are nearly about $3-8 \%$ which play a vital role in providing several immune responses in humans. The levels of these important constituents are known to get reduced due to severities in climate. It is very much important to check the abundance of theses minerals and constituents as they play a major role in growth and development of the crops. This climatic change tends to reduce the available nutrition in the plants making them weak, feeble and prone to death.

In this review our main concern is about different methods in which we can mitigate the losses caused by different climatic conditions especially in turmeric as it is the heritage crop of Indian tradition and is having an immense response in every field of study and in which several modern experiments are conducted to improve the stability, growth and production of this crop by concentrating on its curcumin content along with the important nutritional constituents and their response towards changes in climate is to be investigated. The genome of the turmeric along with its organellar genome and challenges in context to climatic change along with the application of DNA markers and also understanding the genome wide approaches of turmeric under different climatic conditions. Because climate is known to play a major role in the development of turmeric and effects the growth of the crop[13].

\section{Effect of Climate Change on Turmeric}

For several years India's golden spice has been a weapon in treating several diseases and other ailments. It is very popular to reduce the morning sickness in women and also useful as a main ingredient in Indian dishes. Not only this turmeric gained much importance as it is used in treating several akin diseases and is used as a major compound in creams[14]. Curcumin major polyphenol is highly useful in promoting several healthy and beneficial properties in humans. Several cancers and nerve disorders are treated along with other important uses with the help of magic compound called curcumin. Not only this, curcumin is very helpful in promoting proper digestion and clearing ulcers in small intestine by improving he bowel movement. There are several thousands of benefits with the use of curcumin as it is a major compound in turmeric and occupies about $7 \%$ in the entire rhizome. Interestingly, this compound is known to promote orange yellow to golden yellow colour in the rhizomes of the turmeric[15]. 
Lately this crop is known to be affected by the changes in climatic conditions which is clearly observed by its production, Growth and rhizome growth including curcumin content which is major concern to the farmers as well as researchers. There are blandly several effects on the turmeric due to climatic changes which leads to the death of the crop. In some cases the high temperature conditions caused dryness of the crop, yellowing, leaf rolling, drooping of the crop and ultimately leading to the death of the crop[16]. The effect of scorching is clearly observed on the leaves of turmeric and complete yellowing is seen so that the photosynthesis is greatly effected and leading to the less availability of nutrition to the plants. In some areas with constant flooding or increasing soil water content with water stagnation problem poses a major loss to the crop and to the soil. This severe water stagnation conditions or flooding conditions remove lots of nutrients from the soils and also uproot the crop so that its growth is effected and the rhizomes growth is arrested[17]. Also flooding would minimise the growing conditions of the crop and also leads to lodging of the crop. Along with this the incidence of pests and diseases is quite easy as the moisture in the soils attract and permit the growth of several fungal hyphae and harmful microbes. Rotting of stems near the ground level and sometimes rotting of rhizomes underground would effect the yield of the crop which is ultimately due to flooding conditions which is a result of severe climatic changes[18].

In some cases chilling or freezing temperatures would arrets the growth of the crop, if in initial stages the cold conditions effect the germination of rhizomes by arresting the cell division and restricting the availability of the nutrient to the growing plant tissue. Also sometimes the chilling conditions reduce the ability of plant to grow and result in stunted growth of the crop which ultimately leads to less growth of the rhizomes. Also certain microbial growth near the rhizomes is possible due to cool temperatures or else the microbes remain dormant near the rhizomes under cold conditions and start developing once situations are normal[19].

Along with these conditions severe rainfall and emission of unwanted greenhouse gases damage the crop to a maximum extent that the crop is unable to survive and ultimately die. Rainfall effect the crop by reducing the penetration of light to the crops by arresting the photosynthesis of the crops which is believed to be a major threat for the crop. Also the green house gases in the environment interfere with the gaseous exchanges in between various cycles and pollute the crop environment leading to the death of the crop[20].

Table 1: Effect of climatic change in turmeric [20]

\begin{tabular}{|l|l|}
\hline Climate change & Percent effected \\
\hline Rainfall and flooding & $35 \%$ \\
\hline High temperatures & $27 \%$ \\
\hline Chilling temperatures & $18 \%$ \\
\hline Snow falls and hail storms & $7 \%$ \\
\hline Greenhouse gases & $13 \%$ \\
\hline
\end{tabular}

Different climatic conditions have varying effects on the growth and the development of the crop. These climatic conditions occupy different percentages in the development of turmeric crop depending upon the loss they created particularly in turmeric crop. It was observed that the highest negative effect was observed in turmeric in response to high rain fall and flooding conditions of the field which creates several problems of water logging and damages like rotting of the crop ultimately leading to the death of the crop. Also the least negative effect due 
to climatic conditions was observed by snowfalls and hail storms because their occurrence is very rare. High temperatures also show adverse effects on the growth of the crop followed by chilling or cold temperatures and greenhouse gases in turmeric.

Also, the changes in the climatic conditions spoil the crop in different stages. The effect was observed in each stage of the crop effecting the normal growth cycle of this herb[21].

Table 2: Effects of climatic changes in different ways [21]

\begin{tabular}{|l|l|l|}
\hline Climatic changes in the crop & Indirectly effected & Other effects \\
\hline Directly effected & Pest incidence & Increase in food demand \\
\hline Production effected & Fertility of the soil & Unequal distribution \\
\hline Morphological effects & Availability of irrigation & Increased prices \\
\hline Phenotypical effects & Disease onset & Trade related issues \\
\hline Genotypical effects & $\begin{array}{l}\text { Complete loss of soil } \\
\text { microbes }\end{array}$ & Less availability \\
\hline Physiological effects &
\end{tabular}

Several effects were observed due to different climatic conditions. These can be direct or indirect and sometimes may create socio economic related issues. Several morphological, physiological and phenotypical characters of the plants was observed due to severe effect of climatic changes along with incidence of pests and diseases leading to decrease in soil fertility and useful soil microbes. Also, this climatic changes especially in turmeric would like to create horrendous effects in socio economic conditions of the country by reducing the availability thereby increasing the demand and the cost of production and availability. Also, these factors leads to trade related issues because of low or poor quality of the turmeric rhizome and less curcumin content. Like wise several effects were observed in turmeric crop due to climatic changes which is major problem in present cultivation programme.

\section{Turmeric Genome}

In general, the total DNA of a particular organism is known to be its genome size. It is denoted or understood as a single copy of complete genome and is usually measured in picograms or counting total number of nucleotides in that genome[22]. This area of understanding the total genome of a particular crop is very interesting to plan any genetic studies of specific varieties. It was believed by few scientists that larger genome size indicates larger size of gene which takes more time to replicate whereas small genome sized genes take less time and genome specific studies could be carried out easily[23].

There are several sequencing methods discovered to completely understand the genome of a particular plant. The sequencing helps us to understand the arrangement of nucleotides or the order of nucleotides in a particular plants genome which is highly beneficial to do any genome editing methods further[24]. Also, this sequencing also helps in clear understanding of human genome which turned out to a greatest achievement in 2000. Also this sequencing helps to identify the areas of a gene which causes diseases and may cause death of the person so that we can remove such areas from the genome and can synthesize artificially in the place of original gene, through which we can reduce the incidence of diseases in humans. This can be applicable to plants as well[25]. 
Understanding genomes of plants is very much beneficial as the discovery of different genes helps us to investigate different functions of each gene in same species and others. The organisation of the genes together in a super coiling way forms chromosomes which are very helpful in cell division and also maintains hereditary of the cells. Microarray analysis is the key to understand the total genome of a particular plant[26].

As known turmeric is a very important and useful crop in many Indian dishes occupies a major position in cooking and pharmaceuticals the understanding of its genomes very important to analyse any further disease in the crop and also to identify different genes that are responsive to different stresses[27]. The genes that are responsive to different stresses can be seen in different cultivars of turmeric and some other crop species. Certain drought responsive genes like CDPK, CDPK 1 were observed both in turmeric and also in several other crops like soybean, rice, wheat and maize. Also salinity responsive genes like Cypcl and MSA-2 genes and TRE-1 were observed in other cereal crops. These genes that are responsive to different stresses can be seen in other plants in responsive to same stress or another related stress[28].

The identification of such stress responsive genes is possible through analysing turmeric genome and studying it. Based on plant DNA based C-value the total turmeric genome size is around $1.3 \mathrm{Gbp}$ and is a polyploid having $2 \mathrm{n}=63$ chromosomes[29]. Ginger which shares the same family along with turmeric is known to have almost similar genome size which is about $1.5 \mathrm{Gbp}$ very near to turmeric and so known to have same growth and development cycle apart from medicinal and therapeutic properties. Different turmeric species are known to have changes in their diploid chromosome numbers[30].

Table 3: Different turmeric species and variations in chromosome numbers [29]

\begin{tabular}{|l|l|l|}
\hline SPECIES & ORIGIN & $\begin{array}{l}\text { 2NCHROMOSOME } \\
\text { NUMBER }\end{array}$ \\
\hline Curcuma aeruginosa & Thailand & 63 \\
\hline Curcuma amada & India & 42 \\
\hline Curcuma aromatica & India & 86 \\
\hline Curcuma aurantiaca & Bangladesh & 84 \\
\hline Curcuma comosa & Indonesia & 63 \\
\hline Curcuma elata & Thailand & 63 \\
\hline Curcuma Haritha & India & 42 \\
\hline
\end{tabular}

Several turmeric cultivars belonging to same species differ in their diploid chromosome numbers depending the type of species which also effects their medical properties. In few species like C. aromatica chromosome number is as high as $2 \mathrm{n}=86$ and in some other speies like C. haritha and C. amada which belongs to India have less diploid chromosome number about $2 n=42$. Therefor it is clear that the genome sizes of different turmeric cultivars and between the species belonging to the same family i.e., Zingiberaceae vary depending upon the previous breeding populations and varieties.

\section{Organellar Genomes of Turmeric:}

Some amount of DNA is known to be found in the organelles other than nucleus. Certain cell organelles like chloroplast and mitochondria are known to contain certain amount of their own circular DNA. This all is observed outside the nucleus and in the organelles present in the protoplasm or cell fluid[31]. These genomes are also known as extranuclear genes. These genomes are very small in their size but are very much essential as they carry out important 
functions in the cell. Usually, their size ranges between 20-20,000 genomes per cell and it depends upon the type of the cells and the functions they carry. These genomes are very neatly arranged and organized in the nucleoids of the cells which maintains genomes[32].

These organellar genomes are known to provide information regarding the proper function of the particular organelles which ultimately effects the growth of the plants. Sometimes these genomes provide insufficient information may be due to their size in different cells[33]. There are several organelles in a single cell which includes Mitochondria, Chloroplasts, Endoplasmic reticulum, vacuoles, Golgi apparatus etc. excluding chloroplast in plant cells, where out of all these organelles only chloroplast and mitochondria are known to have sufficient amount of organellar genomes and are well maintained throughout generations[34]. The flow of organellar genomes from one generation to another generation is mainly observed due to paternal inheritance especially in chloroplasts and mitochondria. However, sometimes this inheritance is paternal under few cases like if they are interspecific crosses[35]. Also in some cases this inheritance of organellar genomes could be either paternal or bi-parental which is very rarely observed. Mostly the inheritance of these organellar genomes would be effective and transferred efficiently from chloroplasts and mitochondria through maternal inheritance only. Whereas the transfer of organellar genomes from both the parents or only paternal would cause certain aberrations in the genomes which would disturb the functioning of the organism ultimately effecting the cellular functions[36].

These organellar genomes gained much importance in recent years due to their effective and unique functions in the plants as well as in animal cells. These genomes are known to replicate in semi conservative methods in both mitochondria and chloroplasts being liable to mutations[37]. The expression levels and the inheritance of these organellar genomes is different compared to that of nuclear genes. The transcription and the translation of these genomes occurs within these organelles and are not extra-nuclear. Also these organelles are known to present in multiple copuies per organelle mostly through un I parental distribution. The copies of organellar genome sin chloroplast was observed to 15- 35 copies per organelles , whereas 4-5 copies per organelles in case of mitochondria which was seen in yeast cells[38].

These organellar genome are maintained or inherited so that their minimum beneficial function is carried out in the cell shaving these organelles and maintained from generation to generation. These organelles are kwon to have a useful effect on RNA editing and the regulation of genetic code[39]. Turmeric which is the most important crop due to its health benefits and several other properties. The maintenance of the mitochondrial genomes and chloroplast genome are very much important to carry out several functions like gene edition and gene coding which is the major role of these genomes in the cells. The total of 145 genes are present tin chloroplast genomes which encodes for $70 \%$ coding whereas 62 genes are present in mitochondrial genomes that encodes for $10 \%$ of coding in turmeric. Therefore, these organellar genomes are less in number but due to their efficiency and important properties these genomes are given much importance in many important crops like turmeric, ginger, rice, pulses, beans etc. More research needs to be done in analysing the specific organellar genomes sizes of turmeric and several cultivars in turmeric. The understanding of the organellar genomes and the knowledge of their sizes were precisely given by the different sequencing methods which are appropriate for the organellar genomes sequencing[40]. 


\section{Challenges, Priorities and Prospect of Plant Breeding In Turmeric (Limitations of Traditional Turmeric Breeding)}

Turmeric being an important and auspicious crop of Indian culture gained much importance due to its helpful and healthy properties. It is used in varied ways as medicine, food purpose, medicated creams and beauty world[41]. The traditional methods of turmeric were not so appropriate compared to the recent non-conventional methods. The growth of the crop is well maintained under controlled conditions also the produce is of limit as expected due to traditional methods[42].

The soil conditions of turmeric would be maintained properly by irrigations and annual rainfalls. As known the turmeric can grow in different soils but well drained sand or loamy soils are appropriate for the growth of the crop whereas the optimum temperature required for the proper growth of turmeric is around $27-40$ degrees[43]. There are number of cultivars in turmeric which are adaptable to different climatic and soil conditions. These varieties are selected for planting purposes under maintained conditions. The soils are well maintained with proper watering and the field is prepared with $50 \mathrm{~cm}$ gap for the sowing of the turmeric where each seedling is placed in the soil. A total of $3000 \mathrm{Kg} / \mathrm{ha}$ of turmeric seed material is needed for proper sowing in the field[44].

Farm yard manure, compost, NPK fertilizers and certain biofertilizers are added in required quantity to the filed to maintain proper soil conditions and healthy plant growth. Later the crop should be mulched properly using green leaves and weeds are to be removed carefully with proper count of irrigations i.e., 25 irrigations for clay soils and 45 irrigations for sandy loams[45]. Later as a measure of plant protection the crop is applied with certain pesticides like Mancozeb, Bordeaux mixture etc., in required proportions based on the prevailing disease. Also, under pest management practices several strategies are implemented by spraying Quinalphos, Dimethoate etc. in required quantities. These pests are managed with the help of insecticides and some chemicals or sometimes bioinsecticides in Integrated Pest Management process. Now a days usage of bt crops and their productions was increased in India and some parts of the world due to their ease of growth and effectivity in controlling several unwanted pests. But, there are certain questions in case of usage of genetically engineered crops[46].

This disease management under traditional methods is a time taking process and includes several important steps like selection of parents, hybridisation, evaluation of hybrids, testing and release as new cultivars[47]. Following these procedures is time taking and labour intensive. Also, the expected outcome regarding disease management is quiet less compared to newly emerging techniques[48].

Crop breeding methods are very helpful and useful for the farmers as well as breeders to understand the nature of the crop and its adjustability to different environmental and biotic conditions. These breeding methods contribute major advantages towards the crop by making them escape maximum losses during unfavourable conditions. But these methods are not as effective in present conditions due $\mathrm{t}$ increasing environmental stresses and harmful conditions[49]. These methods were sometimes known to reduce the emission of harmful gasses and may reduce the effect of these gases on the plant itself. Understanding proper breeding methods to reduce the negative effects caused by climate is a challenge to many breeders around the world, because climate changes cannot be controlled rather stopped by any mode. The reduce usage of unwanted chemicals or harmful techniques is the only possible way 
to reduce the climate change effect on the growth of turmeric. Reduced usage of carbon, fossil fuels like oil and natural gas would reduce the naturally available non-renewable sources and increases the emission of unwanted and very harmful gasses into the environment which would be a problem to both the plants and ultimately humans. It was known that the U.S. Environmental protection Act came forward and suggested the reduced usage of natural resources under agriculture and animal husbandry to mitigate many losses caused by climate changes[50].

Farming and animal agriculture is one way or the other effecting the climate by the release of harmful gasses like methane from certain crops like rice and certain gases are released from the urine of animals in the field and also the prolonged usage of chemical fertilizers. So to reduce the harmful effects of the environment through climate changes breeders are to develop certain varieties that are tolerant to severe or adverse environmental conditions, so that the growth of the crop, cropping patterns and the yield of the crop will not be effected and can be maintained well. All the losses that are caused due to climate changes are well calculated and proper measures are to be taken to reduce the harmful effects[47,48].

Especially in turmeric the selection of heat tolerant germplasm is beneficial under high temperature conditions. Also, the sowing of the crop after rabi season is much advisable to reduce the losses caused due to chilling and cold stress conditions. Whereas as turmeric is tolerant to few irrigations but not to heavy rainfall conditions which cause yield losses in the crop and shows reduced growth. Under such conditions the field should be maintained well with proper draining system to avoid water logging problem. The presence of water in the field would affect the soil nutrients and also the growth of the plants by spoiling the growing rhizomes and sometimes causing rots in the root areas which would be severe and spread easily form one field to another. To avoid all these losses the sowing of turmeric should be done by the end of winters to escape chilling stresses and also selecting heat tolerant varieties of turmeric that are breaded with heat tolerant parents or genetically engineered to reduce the harmful effects caused by high temperature stresses. Following proper sowing seasons and cropping patterns would reduce the effect of climatic changes in turmeric and many other crops as well[51].

Table 4: Adaptations for climate changes in different crops [48]

\begin{tabular}{|l|l|}
\hline CROP & ADAPTATIONS \\
\hline Maize & Raised bed planting to avoid water logging. \\
\hline Chick pea & Agroforestry to avoid harsh winds. \\
\hline Rice & Direct planting to avoid transplanting losses \\
\hline Cotton & Usage of cultivars that are tolerant ot heat and drought stress. \\
\hline Sugar cane & Pit planting of the crop to avoid water deficit conditions. \\
\hline
\end{tabular}

Proper breeding methods are followed in several other crops to reduce the losses caused by harsh climatic and environmental conditions to reduce the losses of yields. Mostly these plant breeding methods for climatic changes deals with the escape of the cropping season of the plants towards different climate changes. Usage of heat and drought tolerant cultivars reduced the maximum yield losses in cotton, where as in maize water logging is avoided by raised bed planting and also in case of sugar cane and rice water losses are greatly reduced.

Understanding different climatic conditions and breeding different varieties in response to the changes in the environment is quite a challenge in the present India agriculture system , 
especially in crops like turmeric which is a long duration crop that need almost 10-11 months to completely mature and the harvest of rhizomes following plant breeding techniques is a challenge and depending upon certain management practices is very much advisable than to escape the harsh climatic conditions[52]. It was also observed from the table 2 that several crops are following different adaptation methods or management practices to avoid maximum yield losses under unfavourable conditions like high temperature, heat shocks, cold stresses, rainfall, floods and unwanted harmful gasses from the industries[51,52].

\section{Genetic Resources of Curcuma: Diversity, Characterization and Utilization}

Turmeric which belongs to Zingiberaceae family comprises about 80 different rhizomatous herbs that produce useful and important polyphenolic substances that are very much effective in treating several diseases and used as a condiment in many Indian foods[53]. This curcuma can withstand a high temperature of about 55-60 degrees centigrade and cannot withstand very low temperatures below 65 Fahrenheit which would reduce the yield of the crop and sometimes leads to the death of the plants[54].

This turmeric exhibit both intra and inter specific variations along with certain morphological and physiological changes[55]. The variations were also observed for curcumin contents, oleoresins and some vital essential oils in the plants which would reduce with respect to changes in climatic conditions. Different altitudes were known to affect the crop in their production and productivity. Turmeric cultivars grown in different parts of India were known to have different sowing seasons and growing patterns.[56] Also, turmeric cultivars in different parts of the world are known to have different adaptation techniques and are known to follow different breeding methods o mitigate the yield loses. Also the cropping patters, growth cycle and cultivable area along with yield and medicinal properties changes due to different weather conditions prevailing in several regions of world. Also different cultivars exhibit different growing patterns also depending upon the soil type used and soil conditions in India and around the world[57].

Table 5:Genetic diversity of turmeric: Different climate adaptable varieties are found [56]

\begin{tabular}{|l|l|}
\hline DIFFERENT PARTS of INDIA & CULTIVARS GROWN \\
\hline South east coastal plain & Soro, Nilgiri \\
\hline East coastal plain & Puri, kandarpur \\
\hline North eastern ghat & Udaigiri, Rayagada \\
\hline South eastern ghat & Badhangati, Keonjhar \\
\hline Eastern ghat highland & Pottangi, Nbarangpur \\
\hline
\end{tabular}

Different varieties that are tolerant to different environmental conditions and stresses. Most of the varieties through breeding programme are almost all tolerant and capable of withstanding adverse conditions. Such varieties were found in abundance in different parts of India. These cultivars are distributed in different areas of regions of India. This distribution of these cultivars is very important and can be used to promote crossing and improvement in many breeding methods.

Also the characterization of different curcuma species was done by collecting samples from different parts of the country. These cultivars were characterized depending upon their growing period, their adaptations, yield, morphological properties and curcumin content. Understanding 
the cultivar properly along with its beneficial compounds and their compositions is a very important step in characterization of different turmeric cultivars[58]. This characterization is a very useful step as it provides the list of germplasms that are available for carrying out breeding programmes and helps in production of stresses tolerant varieties which can be used for further cultivation process[59].

Table 6:Different turmeric cultivars and their starch content [58]

\begin{tabular}{|l|l|}
\hline CULTIVARS & STARCH CONTENT \\
\hline C.leucorrhiza & 12.3 \\
\hline C.rakhtakanta & 15.0 \\
\hline C.sylvetica & 10.2 \\
\hline C.zedoaria & 14.2 \\
\hline C.longa & 7.2 \\
\hline C.brog & 18 \\
\hline C.aromatica & 15.6 \\
\hline
\end{tabular}

Starch content is considered as a main important biochemical compound in the growth of turmeric because the starch content will ultimately impact the growth of turmeric rhizomes and ultimately affect the amount of curcumin present in the rhizomes. The starch in the plants will be converted into amylase which promote proper nutrition in the turmeric plants and promote the growth of the plants thereby increasing the rhizome growth and nutritional properties of the plants. It was observed rom table 4 that the lowest starch content was observed in c.longa cultivar which we normally grow in several parts of our country[60]. Also C.brog contain high amount of starch which provides maximum nourishment to the growing rhizomes so that the productivity of the crop is more. This cultivar is from Florida, USA and is known to be very effective in growth and medicinal properties compared to other turmeric cultivars around the world. The climatic conditions and nutritional requirements are same for this variety like c.longa. Also, this cultivar takes about 10 months to complete mature and synthesize important nutritional phytochemicals. Few other varieties like c.rakhtakanta and c.zedoaria were known to have almost similar amount of starch which is very much helpful for proper growth of the crop[61].

Turmeric which is a golden spice has many uses in different fields like medicine, ayurvedic and food industries. Several cultivars available around the world are of different and unique properties[62]. The cultivars present in India are known to have different and wonderful properties that are very much helpful to maintain proper health. Mostly curcuma is known for its phytochemical properties and curcuminoids. This herb is praised for its curcumin content which is proven to have several useful and important health benefits and known to treat heart disorders and harmful cancers which is a challenging aspect in the present medicine field[63].

Table 7 Different cultivars and their characteristics [62]

\begin{tabular}{|l|l|}
\hline CULTIVARS & IMPORTANT CHARACTERS \\
\hline IISR Prathibha & $\begin{array}{l}\text { Curcumin content is 6-8 \% and have big } \\
\text { rhizomes. }\end{array}$ \\
\hline Suranjana & Curcumin content 5-7\% and resistant to rots. \\
\hline BSR 2 & Curcumin content 6-2\% and high yielding. \\
\hline Roma & $\begin{array}{l}\text { Curcumin content } 6 \% \text { contain high amount } \\
\text { of essential oils. }\end{array}$ \\
\hline
\end{tabular}




\begin{tabular}{|l|l|}
\hline Rasmi & $\begin{array}{l}\text { Curcumin content is } 7 \% \text { and recovery rate } \\
\text { from heat stress is more. }\end{array}$ \\
\hline Duggirala Red & $\begin{array}{l}\text { Curcumin content is } 5 \% \text { and high yielding } \\
\text { with resistance to leaf blotch and spot. }\end{array}$ \\
\hline Mega turmeric & $\begin{array}{l}\text { Curcumin content } 7.5 \%, \text { high yielding and } \\
\text { bold rhizomes. }\end{array}$ \\
\hline
\end{tabular}

Curcumin content plays a major role is selecting a particular variety as this curcumin is a very important phytochemical which helps build immunity in humans as well as provide several nutritional benefits if consumed. It was observed in table 7 that Mega turmeric is variety containing maximum amount of curcumin which is around $7.5 \%$ which is released from ICAR is known for its high yielding property and maximum size of the rhizome along with its curcumin content. Whereas, Duggirala red cultivar has less curcumin content comparatively. But this cultivar is known for its resistance against certain diseases like leaf spot and leaf blotch which is also a main hindrance in the loss of the yield of the crop. There are few other varieties which are known to have proper curcumin contents and are known for their yield and other properties like resistance to diseases and pests. Out of many cultivars available all over India these were proven to have many important properties and medicinal values due to maximum curcumin content, growth of the crop, size of the rhizomes and importantly tolerance to several abiotic and biotic stresses.

\section{Development and Application of DNA Markers in Context to Turmeric}

A DNA marker is a known gene sequence with known location and used to identify known species or individuals. The variation among the individuals can be observed, the inheritance of these genes present in the same chromosome is observed together in the next generation or in multiplied gene segments[64]. A particular gene whose function is not known yet its location is known can be easily identified with the help of the marker. This marker is a short region which shows polymorphism like insertions, deletions, substitutions between different individuals[65].

Usually, DNA markers are of two types Type 1 which includes coding regions that are usually slightly polymorphic and Type II usually derived from non-coding sequences and ae highly polymorphic which includes micro and mini-satellites. There are several DNA markers which are very useful to detect polymorphisms for a particular sequence in a gene pool[66].

There are several advantages where differences in gene expressions between different traits or difference between normal gene and the gene of interest is well observed. Basically, DNA markers should be polymorphic and needs to be frequently distributed throughout the genome[67]. Also, the markers should be reproducible and should provide maximum exchange between the genotypes. These markers were used identify polymorphic relationship between species[68].

Table 8: Markers: resources for turmeric diversity studies [66] 


\begin{tabular}{|l|l|}
\hline SSR & $\begin{array}{l}\text { Less quantity of DNA is needed and high } \\
\text { maximum genomic abundance. }\end{array}$ \\
\hline ISSR & $\begin{array}{l}\text { Less quantity of DNA is needed and random } \\
\text { distribution of genomes. }\end{array}$ \\
\hline RAPD & $\begin{array}{l}\text { Medium quantity of DNA is needed and } \\
\text { maximum genomic abundance is observed. }\end{array}$ \\
\hline AFLP & $\begin{array}{l}\text { Less sequence information and maximum } \\
\text { genomic abundance. }\end{array}$ \\
\hline RFLP & $\begin{array}{l}\text { Maximum genomic abundance and genomic } \\
\text { distribution. }\end{array}$ \\
\hline
\end{tabular}

There are few DNA markers which are useful in analysing and studying the genetic diversity studies which include SSR's, ISSR's , RAPD's etc., where the distribution of genomes is maximum for almost all the DNA markers where the genes are spread on the chromosomes within different gene clusters[69]. It was observed from table 8 that less quantity of DNA is needed for almost all the markers for analysis and also genome abundance is more for all the markers, whereas RAPD medium quantity of DNA is needed to understand the turmeric diversity studies[70].

\section{Fig 1: Applications of DNA markers.}

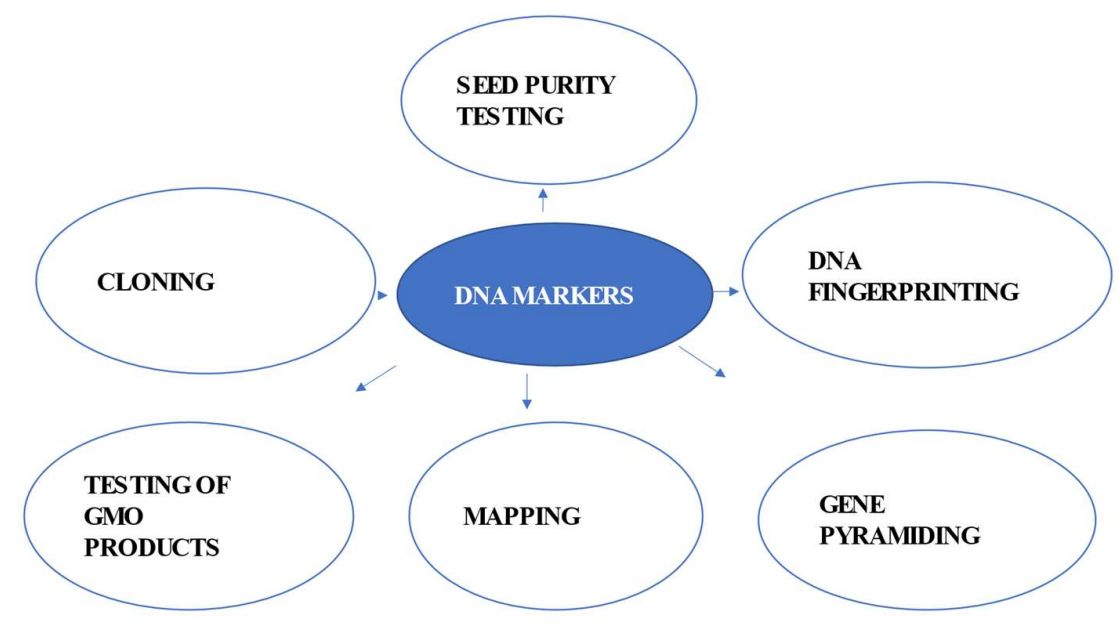

There are several advantages using DNA markers like seed purity testing, DNA fingerprinting, gene pyramiding, Gene mapping, testing of GMO products and cloning which are a major essential thing in breeding of a particular turmeric cultivar. These DNA markers are known to promote complete knowledge regarding genomics in several plant species like tomato, crucifers and different cultivars of turmeric and ginger. High density linkage maps are also constructed which is a major tool for MAS studies and QTL analysis. Also this DNA markers analysis is useful for forensic studies and understanding the fingerprinting of different genotypes along with the proper estimation of distances between different populations that can be derived from Backcrossing, Pedigree analysis, Pure lines etc[71,72]. 


\section{Genome-Wide Approaches}

The genetic variants that are usually associated with diseases or traits were easily identified with the help of genome wide approaches. The variations of the traits that are related to particular diseases is studied using these approaches. These variations can be properly understood and dealt carefully in future to reduce the risks associated with certain unwanted gene sequences in a particular plant or any organism. These studies can be carried out in different cultivars of same species or different plant species under different environmental conditions[73].

This method mainly involves the identification of the diseases through the proper reading and scanning of the genomes. This scanning helps the breeder or scientist to carefully understand the diseases, their nature and ca predict the possible losses associated with such diseases. These studies reveal the presence of the genes that are associated with severe disease forms in living organisms, as the name genome wide itself indicates throughout the DNA[74]. These genome wide studies provide the information regarding all the possible traits associate with a particular genetic locus and the characters associated with those traits. These characters are studied individually by understanding the negativity or the effects of particular genes in the growth of a particular organism[75].

In general these genome wide approaches can be done in two ways one is marker based and other is whole genome, where in marker based genome wide studies larger samples of DNA are considered for the study whereas $n$ case of whole genome based studies it deals with the identification of genomes or genes that deals with unknown or uncharacterized diseases. By doing this the nature of the disease and the possible effects of the diseases on an organism is studied along with the persistence of the disease throughout the generations can be observed and can be arrested further through molecular methods so as to avoid maximum yield losses in case of plants and reduction of health issues in humans[76].

These genome wide studies are based on a population survey of a particular species of plants or all the humans if. These studies are not based on linkage map but can be dealt with the use of association mapping or linkage disequilibrium map. These genome wide studies also deal with the genetic ancestry for a particular population. This can be achieved by comparing the individuals between the populations and also between two different populations. The quantitative estimation of populations along with the ancestral diversity which is the most important step to be carried out[77].

Turmeric which is the most important herb in Indian culture with more than 80 different type of cultivars is known to posses wild relatives with varied characters. The genome wide studies in turmeric are to be conducted properly to understand the genetic diversity, ancestry of the wild relatives, analysis of the population of the turmeric varieties and most importantly the genome sequencing of turmeric, where the entire DNA is analysed to study the presence of any disease causing genes or different traits in the plants[78]. These studies in turmeric helps us to analyse the faulty genes in the sequence and improve the resistance of the plant towards that particular disease through genetic engineering or molecular tools. Thus, genome wide studies play a vital role in understanding the roles of different genes in genomes and helps in 
identification of the genes that cause harmful effects in particular gene loci where the ill effects of the genes can be observed and can be reduced further through molecular approaches[79].

Fig.2: Steps in Genome -Wide Studies:

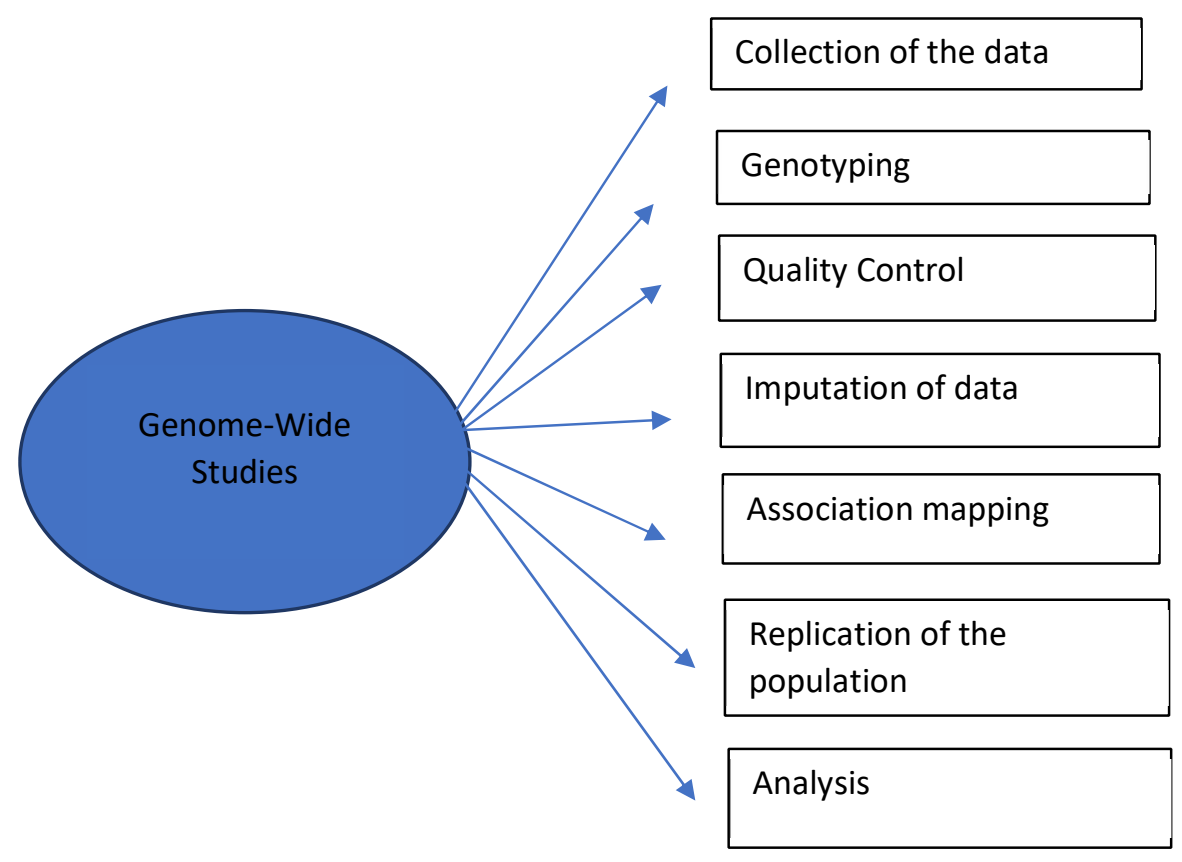

The are a total of seven steps in genome wide studies. From fig 2 it was observed that the collection of data is the initial step where a large number of population is pooled(gene pool), followed by the proper genotyping based on the characters. Later quality control id done by separating the individuals which are of one king from the entire gene pool followed by imputation and association mapping. The replication of the separated population is also important to clearly understand the nature of population in large quantities which was followed by analysis of the result by identifying the proper individuals from the populations leaving the rest of the individuals.

\section{Transcriptomic Approaches:}

These studies can be carried in a particular cell, using high throughput genomics methods like microarray analysis[80]. This study of RNA which is also known as Transcriptomics is studied along with other fields of study like genomics, proteomics and metabolomics. These studies help us to understand the nature of the genes and their respective pathways along with the response of genes with respect to biotic and abiotic stresses. The understanding and the analysis of non-targeted genes or RNA and their study is a complex system and time taking compared to the study of targeted set of RNAs[81].

Transcriptomics is analysed using hybridisation technique and sequence based approach. This hybridisation technique involves the use of DNA microarrays where a microchip is used to detect the genes, where these samples are compared to obtain necessary information. The unique nature of this microarray is that the DNA is arranged in a sequence in an orderly 
manner[82]. Many genes are analysed at a time using this microarray technique whose main principle is hybridisation. Also, the sequence-based method which uses RNA sequence where these genes are subjected to several analytical functions in which the nature of the gene, its expression, its location, its function, structure and its evolution is completely analysed. This whole process of sequence-based method which provides information regarding several aspects of particular gene depends upon the simple sequence alignment methods and the genes were searched using biological databases available from NCBI website. Therefore, the study of RNA either in either ways depend upon simple techniques and this mechanism of expression of the RNA is called as Expression profiling or Transcriptomic profiling[83].

\section{Fig.3 : Process of Transcriptome Analysis:}

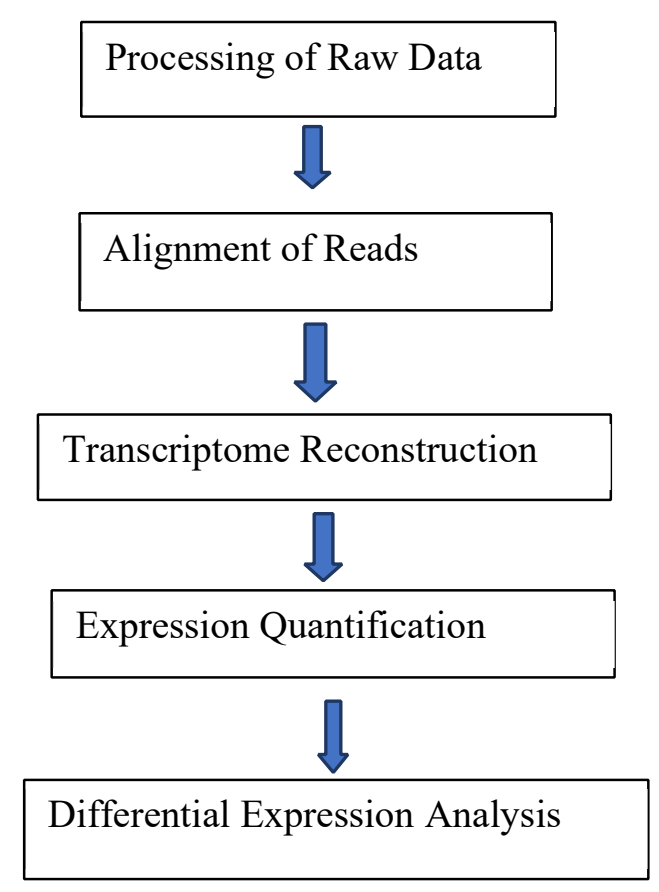

It was understood that the transcriptome analysis involves the proper identification of the raw data which includes the RNA to be analysed, which were then aligned properly to reconstruct the transcriptome which involve the arrangement of the bases in a proper sequence. The expression of the RNA is done by counting the number of reads that are properly arranged in a sequence. This quantification is done using HT Seq- count. From the figure 3 it was observed that the differential expressions of RNA was analysed following all the required steps, where the gene expression is given by using Heatmap which displays the data of gene expression.

Especially in case of turmeric under the influence of several climatic changes, the understanding of different gene is very important due to their expressions and use in uncertain conditions[84]. Different climatic changes trigger different plants responses with respect to the change in the climate. Certain genes are likely to be expressed in cold conditions, some express under hear stress and drought stress individually or sometimes together. Certain gens are responsive under salinity stresses which controls all the plant functions. These responses are very important and the expression of genes helps us understand the ability of the plants to withstand the stress conditions or the climatic changes[85,86,]. 
Therefore, the transcriptome analysis is a wonderful way of understanding the complete gene its expressions, functions and its location ca also be detected which provides a lead towards the growth of the plant and the tolerance capability of the plants[87]. Since turmeric is tolerant to high temperatures but very much sensitive to cold stresses certain stress responsive genes like $\mathrm{CBF}$ genes are regulated so that plant can withstand low temperatures up to a certain level without major damage[88,89]. Also, turmeric can withstand less irrigations but not severe drought conditions where DREB genes are responsive and regulated with respect to drought stresses conditions. All the knowledge regarding the genes and their expressions are well analysed to protect the plants from severe damage[90].

\section{Conclusions and Future Prospects:}

Turmeric which is a rhizomatous herb plays an important role in several area of study like ayurvedic, medicine, beauty products etc., is known for its several benefits in treating many diseases and skin problems. All these benefits form turmeric is obtained from curcumin, which is major polyphenolic compound in turmeric and is proven to posses several benefits. The composition of curcumin varies from one cultivar to another cultivar and also depends upon the environmental factors.

Gradual yield losses and reduced curcumin content was observed in turmeric cultivars due to changing climatic conditions by global warming. These climatic changes have greater impact on the growth and development of the crop effecting the yield and growth of the crop. Different climatic conditions affect the crop in different ways, where high temperatures result in leaf scorching, drying and ultimately death of the crop, whereas the low temperature conditions or frost conditions reduce the essential metabolic pathways making plant unnourished and leading to death. Also, high rainfall and floods leads to rotting of the stem and underground rhizomes sometimes uprooting the crops leading to the yield losses. Therefore, it was understood that any change in the climate would lead to yield losses and damages the crop to maximum extent.

Also, this climate change tends to reduce the growth of the plants and devoid them of their nutrients. These nutrients that are present in the plants are required for their growth and development and also proper growth of the rhizomes with required characters. These nutrients were affected due to climate and restricted root growth is observed. Though the shoot growth does not reduce drastically the size of the leaves and the nutritional qualities in of the plants are greatly affected due to nutritional stress in plants. Therefore these losses can be mitigated by increasing biodiversity, promoting the growth of leguminous crops in the same field and improved fertilizer application technologies so that plant growth remains unchanged even in adverse climatic conditions. Following up the nutritional losses and arresting them to prevent further damage to the plant is the major step in managing and developing climate smart turmeric because nutrition is the important thing for the proper growth of plants.

In our review we focussed on the plant breeding methods that are developed to reduce the losses caused by climatic conditions. Several breeding methods are implemented so far like crop rotation, late sowing of crop, changing cropping season, mixed cropping and certain crossing methods so that the plants can escape harsh climatic changes and continue to develop. Also, certain strategies like severe plant breeding where the varieties were developed by crossing the elite parents so that the offspring would be better from both the parents and multiplied. This is a time taking and labour-intensive method which is not possible for immediate results, so the genetic engineering came into picture to reduce the time, labour and fast product designing along with quality were developed. These genetic engineered varieties 
are well maintained and can be easily multiplied with the help of tissue culture or the particular genes that were designed can be multiplied and transferred to other plants through direct and indirect methods.

This advancement of science in developing new plant varieties through genetic engineering technique which are tolerant to unfavourable conditions have gained much importance in the present era compared to the old plant breeding methods which are not very much effective. In one way or other the plant breeding is less effective compared to biotechnological methods in developing useful traits like disease resistance, pest resistance, abiotic and biotic stress tolerance also enhanced production. There are several areas of development in turmeric with respect to climate changes where the nutritional quality, production, size of the rhizome, curcumin content and other essential oil contents are to be maintained properly or needs to be increase accordingly.

Future Prospects

Several challenges are there in increasing the yield and curcumin contents of the turmeric crop even under harsh climatic conditions in which few of them are,

1. Development of improved and high yielding varieties.

2. Increased quality of rhizomes of turmeric

3. Increased curcumin production along with essential oils.

4. Increased nutritional qualities of plants.

5. Designing transgenic plants to enhance the yields.

6. Developing varieties that can tolerate biotic and abiotic stress up to a maximum level without showing signs of death.

7. Improved crop management practices along with molecular tools,

8. Complete understanding of climate changes and following suitable measures by farmers with the help of biotechnology.

9. Designing gene that are heritable and are highly expressive in protecting the plant under unfavourable conditions.

10. Following certain in-vitro techniques under such circumstances where the conventional methods are not so effective.

11. Isolation of genes that are having desirable properties and introducing them into other organisms making it a transgenic plant so that the productivity could be increased.

Since this rhizomatous herb is very much adaptable to maximum temperature of $45-50$ degrees but not more than that where it starts showing signs of damage and yield losses where the rhizome size and curcumin contents are ultimately affected. To reduce these losses certain plant breeding methods were followed but not very effective and were still showing the reduced yields and growth of the plants. To gain maximum benefits certain biotechnological procedures or methods are to be followed like molecular analysis, proteomic, transcriptomics, genetic engineering, gene transfer methods etc., to gain maximum yields from the plants and also to maintain the flow of the genes from one generation to another generation. Due to the adaption of advanced plant breeding methods and application of molecular techniques makes the plant more tolerant to several climatic changes and promote increased nutrient constituents. Therefore the increase in the nutrient constituents of the plants makes the plants more beneficial in terms of food and for medicinal purpose.

The idea of smart turmeric with respect to climatic changes was achieved through molecular biology techniques where the time consumption and labour requirement is low. 
The advanced methods like molecular biology and genetic engineering gained much importance compared to plant breeding methods due to its less effectivity in crop production and time consumption.

By understanding these problems and reduced yields in turmeric due to harsh effects by the climate changes like drought, heat, floods, rainfall and chilling temperatures gene manipulations were done so that genes respond according to the stress and protect the crop from yield losses which in turn benefits the farmers and also helps in maintaining healthy soil conditions. By this we can conclude that present and advanced biotechnology is giving more output compared to conventional methods and these molecular methods are to be followed to achieve smart turmeric crop which is highly tolerant to any unfavourable conditions especially sudden climatic changes, where the crop can tolerate to certain extent without maximum damage and yield losses.

\section{References:}

1. Andy WKY et al. "Curcumin: Total-scale analysis of scientific literature." Molecules, vol. 24, no. 7 (April 9, 2019): 1393

2. Lorinczova HT et al. "Co-administration of iron and a bioavailable curcumin supplement increases serum BDNF levels in healthy adults." Antioxidants, vol. 9, no. 8 (July 22, 2020): 645

3. Lorinczova HT et al. "Acute administration of bioavailable curcumin alongside ferrous sulphate supplements does not impair iron absorption in healthy adults in a randomised trial." Nutrients, vol. 13, no. 7 (July 3, 2021): 2300

4. Banji D et al. "Neuroprotective effect of turmeric extract in combination with its essential oil and enhanced brain bioavailability in an animal model." BioMed Research International. Published online January 26, 2021.

5. Bresciani $\mathrm{L}$ et al. "The effect of formulation of curcuminoids on their metabolism by human colonic microbiota." Molecules, vol. 25, no. 4 (February 19, 2020): 940

6. Oliver JM et al. "Novel form of curcumin improves endothelial function in young, healthy individuals: A double-blind placebo controlled study." Journal of Nutrition and Metabolism. Published online August 17, 2016.

7. Jäger R et al. "Eight weeks of a high dose of curcumin supplementation may attenuate performance decrements following muscle-damaging exercise." Nutrients, vol. 11, no. 7 (July 23, 2019): 1692

8. Mallard AR et al. "Curcumin improves delayed onset muscle soreness and postexercise lactate accumulation." Journal of Dietary Supplements. Published online July 24, 2020.

9. Kassebaum N.J. The Global Burden of Anemia. Hematol. Oncol. Clin. 2016;30:247308. doi: 10.1016/j.hoc.2015.11.002. - DOI - PubMed

10. Williams A.M., Addo O.Y., Grosse S.D., Kassebaum N.J., Rankin Z., Ballesteros K.E., Olsen H.E., Sharma A.J., Jefferds M.E., Mei Z. Data needed to respond appropriately to anemia when it is a public health problem. Ann. N. Y. Acad. Sci. 2019;1450:268-280. doi: 10.1111/nyas.14175. - DOI - PubMed

11. Lopez A., Cacoub P., Macdougall I.C., Peyrin-Biroulet L. Iron deficiency anaemia. Lancet. 2016;387:907-916. doi: 10.1016/S0140-6736(15)60865-0. - DOI - PubMed

12. E. Inan-Eroglu and A. Ayaz, "Is aluminum exposure a risk factor for neurological disorders?" Journal of Research in Medical Sciences : The Official Journal of Isfahan University of Medical Sciences, vol. 23, no. 1, p. 51, 2018. 
13. Myers SS, Zanobetti A, Kloog I, Bloom AJ, Carlisle EA, Dietterich LH, et al. (2014) Rising CO2 threatens food quality. Nature 510: 139-142. Link: https://bit.ly/3hHQ39y

14. Pino J.M.V., Da Luz M.H.M., Antunes H.K.M., Giampá S.Q.D.C., Martins V.R., Lee K.S. Iron-Restricted Diet Affects Brain Ferritin Levels, Dopamine Metabolism and Cellular Prion Protein in a Region-Specific Manner. Front. Mol. Neurosci. 2017;10:145. doi: 10.3389/fnmol.2017.00145. - DOI - PMC - PubMed

15. Gonzalez A., Moya-Alvarado G., Gonzalez-Billaut C., Bronfman F.C. Cellular and molecular mechanisms regulating neuronal growth by brain-derived neurotrophic factor. Cytoskeleton. 2016;73:612-628. doi: 10.1002/cm.21312. - DOI - PubMed

16. Radak Z., Suzuki K., Higuchi M., Balogh L., Boldogh I., Koltai E. Physical exercise, reactive oxygen species and neuroprotection. Free. Radic. Biol. Med. 2016;98:187196. doi: 10.1016/j.freeradbiomed.2016.01.024. - DOI - PubMed

17. Jiang H., Wang J., Rogers J., Xie J. Brain Iron Metabolism Dysfunction in Parkinson's Disease. Mol. Neurobiol. 2017;54:3078-3101. doi: 10.1007/s12035-0169879-1. - DOI - PubMed

18. Kulkarni S.K., Dhir A., Akula K.K. Potentials of Curcumin as an Antidepressant. [(accessed on 8 April 2020)]; Available online: https://www.hindawi.com/journals/tswj/2009/624894/

19. Mursaleen L., Somavarapu S., Zariwala M.G. Deferoxamine and Curcumin Loaded Nanocarriers Protect Against Rotenone-Induced Neurotoxicity. J. Parkinsons Dis. 2020;10:99-111. doi: 10.3233/JPD-191754. - DOI - PubMed

20. Sarraf P., Parohan M., Javanbakht M.H., Ranji-Burachaloo S., Djalali M. Short-term curcumin supplementation enhances serum brain-derived neurotrophic factor in adult men and women: A systematic review and dose-response meta-analysis of randomized controlled trials. Nutr. Res. 2019;69:1-8. doi: 10.1016/j.nutres.2019.05.001. - DOI - PubMed

21. Briskey D., Sax A., Mallard A.R., Rao A. Increased bioavailability of curcumin using a novel dispersion technology system (LipiSperse ${ }^{\circledR}$ ) Eur. J. Nutr. 2019;58:20872097. doi: 10.1007/s00394-018-1766-2. - DOI - PubMed

22. Chakraborty, A., Kundu, S., Mukherjee, S. \& Ghosh, B. Endophytism in Zingiberaceae: Elucidation of Beneficial Impact. in Endophytes and Secondary Metabolites https://doi.org/10.1007/978-3-319-90484-9 31 (2019).

23. Berini, J. L. et al. Combinations of abiotic factors differentially alter production of plant secondary metabolites in five woody plant species in the boreal-temperate transition zone. Front. Plant Sci. https://doi.org/10.3389/fpls.2018.01257 (2018).

24. Singh, N. \& Sharma, A. Turmeric (Curcuma longa): miRNAs and their regulating targets are involved in development and secondary metabolite pathways. $C R$ Biol. https://doi.org/10.1016/j.crvi.2017.09.009 (2017).

25. Gupta, A. et al. Association of flavonifractor plautii, a flavonoid-degrading bacterium, with the gut microbiome of colorectal cancer patients in India. mSystems https://doi.org/10.1128/msystems.00438-19 (2019).

26. Rahmani, A., Alsahli, M., Aly, S., Khan, M. \& Aldebasi, Y. Role of curcumin in disease prevention and treatment. Adv. Biomed. Res. https://doi.org/10.4103/abr.abr_147_16 (2018).

27. Wang, J. et al. Enzymatic formation of curcumin in vitro and in vivo. Nano Res. https://doi.org/10.1007/s12274-018-1994-z (2018).

28. Pellicer, J. \& Leitch, I. J. The Plant DNA C-values database (release 7.1): an updated online repository of plant genome size data for comparative studies. New Phytol. https://doi.org/10.1111/nph.16261 (2020). 
29. Pellicer, J. \& Leitch, I. J. The Plant DNA C-values database (release 7.1): an updated online repository of plant genome size data for comparative studies. New Phytol. https://doi.org/10.1111/nph.16261 (2020).

30. Anamthawat-Jónsson, K. \& Umpunjun, P. Polyploidy in the ginger family from Thailand. in Chromosomal Abnormalities https://doi.org/10.5772/intechopen.92859 (2020).

31. Kolmogorov, M., Yuan, J., Lin, Y. \& Pevzner, P. A. Assembly of long, error-prone reads using repeat graphs. Nat. Biotechnol. https://doi.org/10.1038/s41587-019-0072$\underline{8}(2019)$.

32. Weib, C. L., Pais, M., Cano, L. M., Kamoun, S. \& Burbano, H. A. nQuire: A statistical framework for ploidy estimation using next generation sequencing. $B M C$ Bioinformatics https://doi.org/10.1186/s12859-018-2128-z (2018).

33. Ranallo-Benavidez, T. R., Jaron, K. S. \& Schatz, M. C. GenomeScope 2.0 and Smudgeplot for reference-free profiling of polyploid genomes. Nat. Commun. https://doi.org/10.1038/s41467-020-14998-3 (2020).

34. Flynn, J. M. et al. RepeatModeler2 for automated genomic discovery of transposable element families. Proc. Natl. Acad. Sci. USA https://doi.org/10.1073/pnas.1921046117 (2020).

35. Emms, D. M. \& Kelly, S. OrthoFinder: Phylogenetic orthology inference for comparative genomics. Genome Biol. (2019), https://doi.org/10.1186/s13059-0191832-y.

36. Laetsch, D. R. \& Blaxter, M. L. KinFin: Software for taxon-aware analysis of clustered protein sequences. G3 Genes, Genomes, Genet. https://doi.org/10.1534/g3.117.300233 (2017).

37. Ren, R. et al. Widespread whole genome duplications contribute to genome complexity and species diversity in angiosperms. Mol. Plant https://doi.org/10.1016/j.molp.2018.01.002 (2018).

38. Ruan, J. et al. Jasmonic acid signaling pathway in plants. Int. J. Mol. Sci. https://doi.org/10.3390/ijms20102479 (2019).

39. Zhang, L., Paasch, B. C., Chen, J., Day, B. \& He, S. Y. An important role of 1-fucose biosynthesis and protein fucosylation genes in Arabidopsis immunity. New Phytol. https://doi.org/10.1111/nph.15639 (2019).

40. Qi, F. \& Zhang, F. Cell cycle regulation in the plant response to stress. Front. Plant Sci. https://doi.org/10.3389/fpls.2019.01765 (2020).

41. Varshney RK, Singh VK, Kumar A, Powell W, Sorrells ME (2018) Can genomics deliver climate-change ready crops. Curr Opin Plant Biol 45: 205-211. Link: https://bit.ly/3wJ2TbO

42. Scheben A, Wolter F, Batley J, Puchta H, Edwards D (2017) Towards CRISPR/ Cas crops-bringing together genomics and genome editing. New Phytol 216: 682-698. Link: https://bit.ly/3ekptRR

43. Waltz E (2018) With a free pass, CRISPR-edited plants reach market in record time. Nat Biotechnol 36: 6-7. Link: https://bit.ly/3xMukmi

44. . Bernhard GH, Neale RE, Barnes PW, Neale PJ, Zepp RG, et al. (2020) Environmental effects of stratospheric ozone depletion, UV radiation and interactions with climate change. Photochem Photobiol Sci 19: 542-584. Link: https://rsc.li/2TeJQbH

45. . Eigenbrode SD, Binns WP, Huggins DR (2018) Confronting climate change challenges to dryland cereal production: A call for collaborative, transdisciplinary research, and producer engagement. Front Ecol Evol 5: 164. Link: https://bit.ly/3rchzzd 
46. Wang J, Vanga SK, Saxena R, Orsat V, Raghavan V (2018) Effect of climate change on the yield of cereal crops: A review. Climate 6: 41. Link: https://bit.ly/3wGEjIB

47. Willett W, Rockström J, Loken B, Springmann M, Lang T, et al. (2019) Food in the Anthropocene: the EAT-Lancet Commission on healthy diets from sustainable food systems. Lancet 393P: 447-492. Link: https://bit.ly/3z7jOpZ

48. Ahmed S (2018) Assessment of urban heat islands and impact of climate change on socioeconomic over Suez Governorate using remote sensing and GIS techniques. Egyptian Journal of Remote Sensing and Space Science 21: 15-25. Link: https://bit.ly/3ritWcT

49. Rahman MH, Ahmad A, Wang X, Wajid A, Nasim W, et al. (2018) Multimodel projections of future climate and climate change impacts uncertainty assessment for cotton production in Pakistan. Agricultural and Forest Meteorology 253: 94-113. Link: https://bit.ly/3ifdndO

50. Senapati N, Stratonovitch P, Paul MJ, Semenov MA (2019) Drought tolerance during reproductive development is important for increasing wheat yield potential under climate change in Europe. J Exp Bot 70: 2549-2560. Link: https://bit.ly/2UOXwe7

51. Yadav V, Kaushik P, others. Phytochemicals against COVID-19 and a gap in clinical investigations: An outlook. Indian Journal of Biochemistry and Biophysics (IJBB). 2021;58(5):403-7.

52. Yadav V, Jha R, Kaushik P, others. Biochemical composition of potato biowaste of popular North Indian cultivars. Indian Journal of Biochemistry and Biophysics (IJBB). 2021;58(1):100-4.

53. Verma S, Wani IA, Khan S, Sharma S, Kumari P, Kaushik P, et al. Reproductive Biology and Pollination Ecology of Berberis lycium Royle: A Highly Valued Shrub of Immense Medicinal Significance. Plants. 2021;10(9):1907.

54. Sharma M, Kaushik P, Chawade A. Frontiers in the Solicitation of Machine Learning Approaches in Vegetable Science Research. Sustainability. 2021;13(15):8600.

55. Sharma M, Kaushik P. Vegetable Phytochemicals: An Update on Extraction and Analysis Techniques. Biocatalysis and Agricultural Biotechnology. 2021;102149.

56. Sharma M, Kaushik P. Biochemical Composition of Eggplant Fruits: A Review. Applied Sciences. 2021;11(15):7078.

57. Sharma M, Kaushal R, Kaushik P, Ramakrishna S. Carbon Farming: Prospects and Challenges. Sustainability. 2021;13(19):11122.

58. Sharma M, Dhaliwal I, Rana K, Delta AK, Kaushik P. Phytochemistry, Pharmacology, and Toxicology of Datura Species-A Review. Antioxidants. 2021;10(8):1291.

59. Priyanka V, Kumar R, Dhaliwal I, Kaushik P. Germplasm Conservation: Instrumental in Agricultural Biodiversity-A Review. Sustainability. 2021;13(12):6743.

60. Priyanka V, Goel N, Dhaliwal I, Sharma M, Kumar R, Kaushik P. Epigenetics: A Key to Comprehending Biotic and Abiotic Stress Tolerance in Family Poaceae. 2021;

61. Malhi GS, Kaur M, Kaushik P. Impact of climate change on agriculture and its mitigation strategies: A review. Sustainability. 2021;13(3):1318.

62. Malhi GS, Kaur M, Kaushik P, Alyemeni MN, Alsahli AA, Ahmad P. Arbuscular mycorrhiza in combating abiotic stresses in vegetables: An eco-friendly approach. Saudi Journal of Biological Sciences. 2021;28(2):1465.

63. Kumar A, Kaushik P. Heat Stress and its Impact on Plant Function: An Update. 2021;

64. Kaushik P, Yadav V, Singh G, Jha R, others. Visiting Bael (Aegle marmelos) as a protective agent against COVID-19: A review. Indian Journal of Traditional Knowledge (IJTK). 2021;19:S-153. 
65. Kaushik P, Sharma V, Saini I, Yadav V, Jayaswal D, Singh G, et al. Impact of COVID-19 pandemic on vegetable sector and its allies. Indian Journal of Traditional Knowledge (IJTK). 2021;19:S-177.

66. Kaushik P. Precision Vegetable Farming Technologies: An Update. 2021;

67. Gupta R, Kaushik P. Phyto-Potential of Allium cepa and Allium sativum. 2021; DOI: 10.5772/intechopen.98374

68. Dhaliwal SK, Salaria P, Kaushik P. Pea Seed Proteins: A Nutritional and Nutraceutical Update. In: Grain and Seed Proteins Functionality. IntechOpen; 2021.

69. Sharma I, Dhaliwal IK, Bijalwan P, Yadav VK, Kaushik P. A Brief Perspective on Lost Traditional Grains and Food Habits of Indians. Int J Curr Microbiol App Sci. 2020;9(12):2295-305.

70. Saini I, Rani K, Gill N, Sandhu K, Bisht N, Kumar T, et al. Significance of Arbuscular Mycorrhizal Fungi for Acacia: A Review. Pakistan Journal of Biological Sciences: PJBS. 2020;23(10):1231-6.

71. Saini I, Chauhan J, Kaushik P. Medicinal value of domiciliary ornamental plants of the Asteraceae family. Journal of Young Pharmacists. 2020;12(1):3

72. Kesh H, Kaushik P. Visiting Bitter Gourd (Momordica charantia) from a Breeding Perspective: A Review. 2020;

73. Kaushik P, Kumar P, Kumar S, others. Enhancement of chlorogenic content of the eggplant fruit with eggplant hydroxycinnamoyl CoA-quinate transferase gene via novel agroinfiltration protocol. Pharmacognosy Magazine. 2020;16(5):450.

74. Kaushik P. Transcriptome Analysis of the Eggplant Fruits Overexpressing a Gene of Chlorogenic Acid Pathway. bioRxiv. 2020;

75. Kaushik P. Characterization of Cultivated Eggplant and its Wild Relatives Based on Important Fruit Biochemical Traits. Pakistan Journal of Biological Sciences: PJBS. 2020;23(9):1220-6.

76. Dhaliwal SK, Talukdar A, Gautam A, Sharma P, Sharma V, Kaushik P. Developments and prospects in imperative underexploited vegetable legumes breeding: a review. International Journal of Molecular Sciences. 2020;21(24):9615.

77. Chauhan J, Yadav V, Saini I, Jha R, Tanwar A, Kaushik P. Effect of fungal pretreatment on Solanum nigrum L. leaves biomass aimed at the bioadsorption of heavy metals. 2020;

78. Brar NS, Saini DK, Kaushik P, Chauhan J, Kamboj NK. Directing for higher seed production in vegetables. Agronomy-Climate Change \& Food Security. 2020;55.

79. Brar NS, Kumar T, Kaushik P. Integration of technologies under climate change for profitability in vegetable cultivation: an outlook. 2020;

80. Sinha S, Sandhu K, Bisht N, Naliwal T, Saini I, Kaushik P. Ascertaining the paradigm of secondary metabolism enhancement through gene level modification in therapeutic plants. Journal of Young Pharmacists. 2019;11(4):337.

81. Saini I, Kaushik P, Saini BL. Role of Indian Women in Conservation of Biodiversity. Int J Curr Microbiol App Sci. 2019;8(4):63-8.

82. Kaushik P, Saini DK. Silicon as a vegetable crops modulator-A review. Plants. 2019;8(6):148.

83. Kaushik P, Saini DK. Sequence analysis and homology modelling of SmHQT protein, a key player in chlorogenic acid pathway of eggplant. bioRxiv. 2019;599282.

84. Kaushik P, Kumar S. Data of de novo assembly of fruit transcriptome in Aegle marmelos L. Data in brief. 2019;25:104189.

85. Kaushik P. Standardisation of an Agroinfiltration Protocol for Eggplant Fruits and Proving its Usefulness by Over-expressing the SmHQT Gene. 2019; 
86. Kaushik P. Genetic analysis for fruit phenolics content, flesh color, and browning related traits in eggplant (Solanum melongena). International journal of molecular sciences. 2019;20(12):2990.

87. Brar NS, Kaushik P, Dudi BS. Assessment of natural ageing related physiobiochemical changes in onion seed. Agriculture. 2019;9(8):163.

88. Kaushik P, Kumar S. Transcriptome analysis of bael (Aegle marmelos (L.) corr.) a member of family Rutaceae. Forests. 2018;9(8):450.

89. Kaushik P, Kumar S. Data of de novo assembly of the leaf transcriptome in Aegle marmelos. Data in brief. 2018;19:700-3.

90. Zhao Y, Zhang S, Cannistraci CV, Han J-DJ. 2021b. De novo spatial reconstruction of single cells by developmental coalescent embedding of transcriptomic networks. Preprintsdoi:10.20944/preprints202103.0196.v1 